\title{
Male mites (Varroa destructor) perceive the female sex pheromone with the sensory pit organ on the front leg tarsi
}

\author{
Claudia Katharina HÄußermanN ${ }^{1}$, Bettina ZIegelmanN ${ }^{1}$, Paavo BergmanN ${ }^{2}$, \\ Peter RosenKRANZ ${ }^{1}$ \\ ${ }^{1}$ Apicultural State Institute, University of Hohenheim, 70599, Stuttgart, Germany \\ ${ }^{2}$ State Museum of Natural History Stuttgart, 70191, Stuttgart, Germany
}

Received 7 July 2014 - Revised 30 March 2015 - Accepted 2 April 2015

\begin{abstract}
Varroa destructor males are attracted by a volatile sex pheromone of female mites. We assume that this pheromone is perceived by the sensory pit organ on the front leg tarsi. To test this hypothesis, the front legs of the males were varnished with nail polish. The behavior of the thus treated males toward attractive female mites was analyzed in our mating bioassay and compared to untreated control males and to males with varnished idiosoma. The control males with the varnished idiosoma revealed the same distinct copulation behavior as untreated males whereas the males with the varnished front legs did not show copulation attempts any more. Hence, the sensory pit organ is responsible for the perception of female signals that elicit the copulation behavior. Additionally, a first scanning electron microscopy (SEM) analysis is presented to characterize the male sensory pit organ.
\end{abstract}

\section{Varroa destructor / sex pheromone / male / sensory pit organ / mating behavior}

\section{INTRODUCTION}

In the Western honey bee (Apis mellifera), yearly treatments against the parasitic mite Varroa destructor (Anderson and Trueman 2000) are required in order to prevent the collapse of the colony (Boecking and Genersch 2008; Genersch et al. 2010; Le Conte et al. 2010). A reasonable number of biotechnical control methods and chemical compounds are available to keep the mite population below the damage threshold (reviewed in Rosenkranz et al. 2010). Several synthetic acaricides like coumaphos, amitraz, and pyrethroids as well as natural substances like formic acid, oxalic acid, or thymol are used in beekeeping practice. However, no

Corresponding author: C. Häußermann, Claudia.Haeussermann@uni-hohenheim.de Manuscript editor: Yves Le Conte biological control method has been developed so far. The identification of the female sex pheromone of $V$. destructor (Ziegelmann et al. 2013a, b) and the first successful application of the pheromone in a honey bee colony (Ziegelmann and Rosenkranz 2014) represent a first promising approach. The aim is to disrupt the male's mating behavior through an overdosed application of the sex pheromone and thereby reduce the reproductive success of the Varroa female. Unmated Varroa females will either disappear from the population (Garrido and Rosenkranz 2004; Frey et al. 2013) or are at least unable to lay fertilized female eggs during the next reproductive cycle (Rehm and Ritter 1989; Donzé and Guerin 1994; Donzé et al. 1996).

The reproductive cycle of the female mite starts with the entry into a brood cell containing a fifth instar larva shortly before cell capping (reviewed in Dillier et al. 2006; Rosenkranz et al. 2010). Seventy hours after the capping of the brood cell, the mother mite starts egg laying whereby five to six eggs can be laid in 30-h intervals (Ifantidis 
1983, 1990; Martin 1994). The first egg is haploid and develops into a male mite whereas the following eggs are diploid and develop into female mites (Rehm and Ritter 1989; Ifantidis 1990; Martin 1994). The ontogenetic development of the mites continues from an egg-larva over protonymph, protochrysalis, deutonymph, and deutochrysalis to the adult stage. With the last molt, the mites become sexually mature whereby the males reach adulthood about $20 \mathrm{~h}$ earlier as the first female offspring (Donzé et al. 1996). Immediately after the adult molt, the female mite becomes attractive to the male and elicits the typical cascade of the mating behavior of the male: After some movements around an attractive female, the male mite mounts the dorsum and finally moves sideward to the female's venter in order to transfer the spermatophore. This so-called "tip-over movement" from the dorsum to the venter is an imperative prerequisite for a successful copulation and is exclusively performed toward an attractive female or in the presence of components of the female sex pheromone (Ziegelmann et al. 2013b).

During the searching and mounting phase, the male mites extend their front legs in the air and move them slightly in different directions similar to the antenna in insects. On the front leg tarsi of $V$. destructor females, a sensory pit organ has been described (Ramm and Böckeler 1989; Dillier et al. 2006) that resembles the structure of the Haller's organ found in ticks (Hess and Vlimant 1982; Sonenshine et al. 1986; Dillier et al. 2006). The sensory pit organ of V. destructor females comprises a number of hair sensilla that are considered to enable the mites to perceive temperature, air humidity, and olfactory and gustatory cues (Ramm and Böckeler 1989; Dillier et al. 2006). The sensilla in the pit organ of female mites were classified into two groups of sensilla depending on their distribution over the pit organ: The inner pit sensilla are named S1 to S9 whereas the edge bristles surrounding the tarsal pit are named R1 to R9 (Ramm and Böckeler 1989).

So far, nothing is published on a male sensory pit organ except one brief comment by Ramm and Böckeler (1989). It is also unknown which sensory organ(s) Varroa males use for their chemotactic orientation within the sealed brood cell.
Here we performed an experiment to proof the role of the male front legs in the identification of the attractive female $V$. destructor and present a first characterization of the sensory organ by scanning electron microscope analysis.

\section{MATERIAL AND METHODS}

\subsection{Varroa mites}

All mites used were taken from A. mellifera hives from the Apicultural State Institute, University of Hohenheim. Freshly molted adult females and adult males were taken from brood cells approximately 10 days after cell capping and used for the bioassay. Adult males were used for the scanning electron microscope analysis. For the differentiation of sex and age of the mites, see Rosenkranz et al. (2010).

\subsection{Bioassay}

The bioassay is described in detail by Ziegelmann et al. (2013a). Briefly, plastic queen cell cups (Nicot system ${ }^{\circledR}$, Karl Jenter, Metzingen) closed by a cover slip were used as a test arena (Figure 1). To prevent any odor contamination, new cups were used for each assay.

One freshly molted adult female mite and one adult male mite were put together into the arena (Figure 2). The behavior of the adult male mites toward the adult females was observed for $300 \mathrm{~s}$ at a temperature of 28 $30{ }^{\circ} \mathrm{C}$. During this time, the following behavioral attributes of the male were recorded with the Observer software (Noldus Information Technology, version:

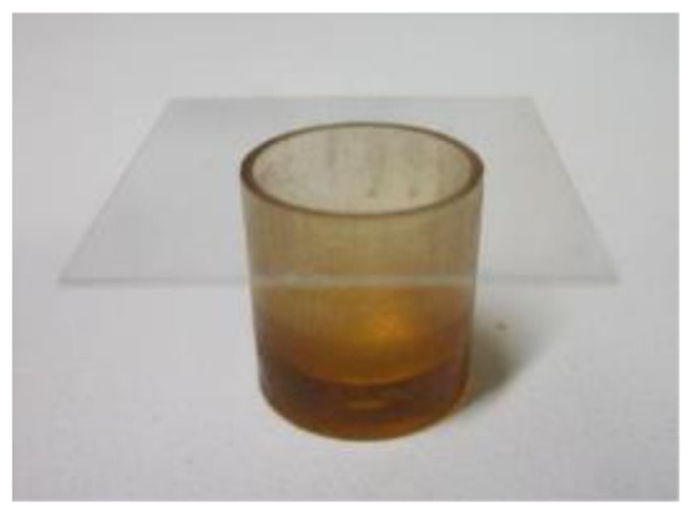

Figure 1. Test arena: plastic queen cell cup with cover slip. Size: $1 \mathrm{~cm}$ in diameter and $1 \mathrm{~cm}$ in height. 
a

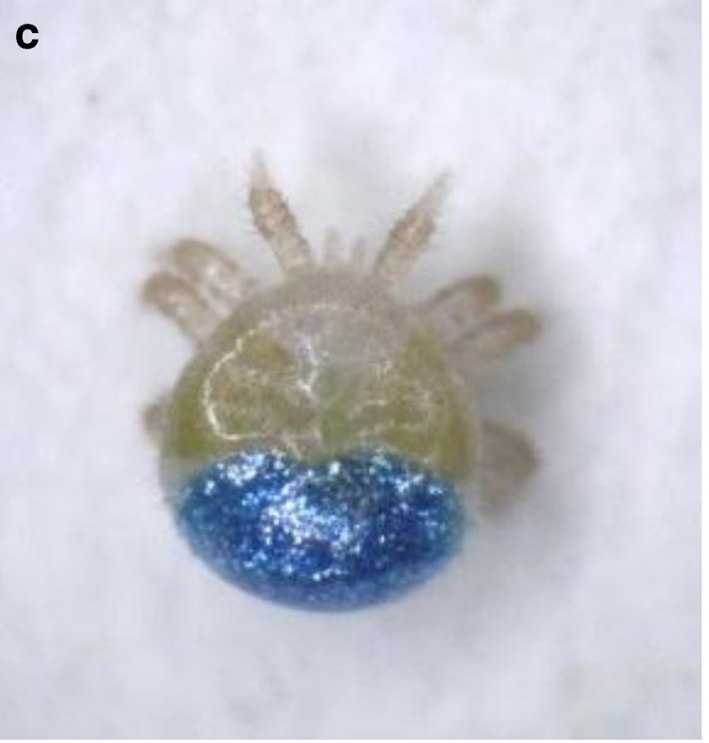

b

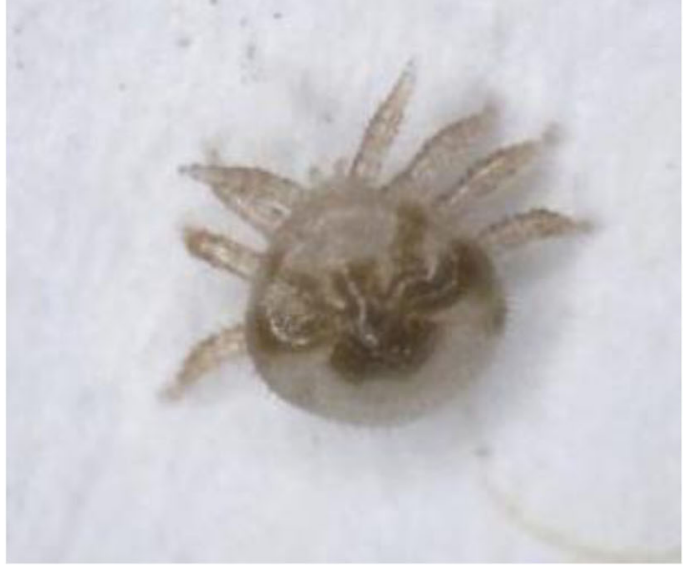

d

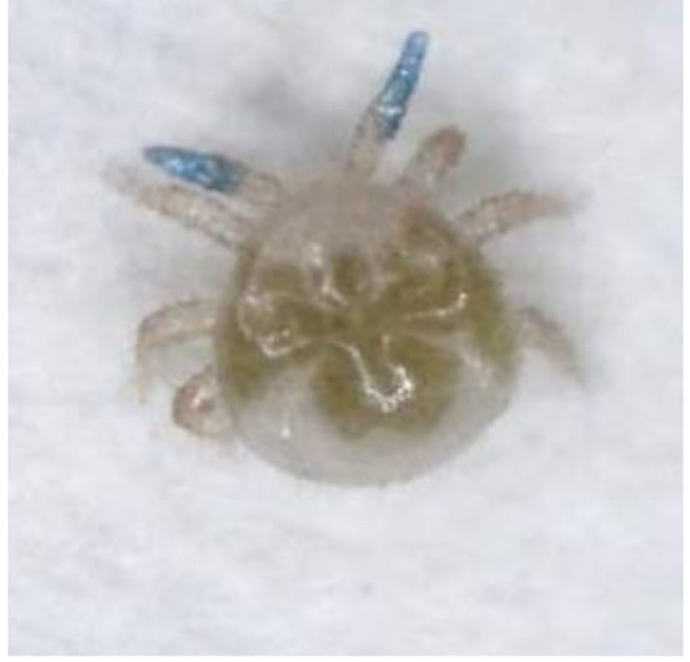

Figure 2. Mites used for the bioassay. a Freshly molted female mite (size $1.1 \times 1.6 \mathrm{~mm}$ ). b Control 1: male mite (size $0.8 \times 0.7 \mathrm{~mm}$ ). c Control 2: male mite with varnished idiosoma. d Male mite with varnished front legs.

28.03.1991): (1) movement toward/around the female and palpating the female, (2) mounting the female's dorsum, and (3) copulation attempt. "Copulation attempt" is defined by the typical movement of the male from the dorsum to the ventral site of the female; this behavior is exclusively performed on attractive $V$. destructor females or in the presence of the female sex pheromone (Ziegelmann et al. 2013a, b). It should be noted that the last step of the mating behavior - the transfer of the spermatophore - cannot be observed within a bioassay.
All mites were used for one trial only, and 16 to 24 replicates were performed for the three test series (two control series and one test series with manipulated front legs).

\subsection{Manipulation of male mites for the bioassay}

To prevent the perception of any volatiles by sensilla on the front leg tarsi, the front legs of male mites were completely varnished with commercial nail polish 
(INTERCO Cosmetics, Wiesbaden, Germany; Figure 2).

While painting the front legs of the males with nail polish, the males were put on a cold thermal pack to calm them down for easier handling. The nail polish was painted on the front legs with a fine needle. After this procedure the male mites were put in a test arena for at least $5 \mathrm{~min}$ at a temperature of about $30^{\circ} \mathrm{C}$ to let them dry and recover from cooling down. To evaluate a potential negative effect of the treatment itself in a further group of males, the legs remained untreated but the posterior half of the idiosoma was varnished with the same nail polish. Finally, a completely untreated group of males was used as a second control.

\subsection{Data analysis}

The behavioral data were analyzed with the statistic software SPSS (Version 22.0). At first, the data sets were checked for normal distribution by the Kolmogorov-Smirnov Test. Because normal distribution could not be confirmed, we used the nonparametric Kruskal-Wallis test for statistical analysis. Differences between groups with $P<0.05$ were considered statistically significant. Box plot graphs were compiled with SPSS.

\subsection{Scanning electron microscopy}

The specimens used for scanning electron microscopy (SEM) were fixed with formaldehyde-ethanol-acetic acid fixation for $24 \mathrm{~h}$ and stored in ethanol (96\%). Before drying the specimens, they were put in ethanol $(100 \%)$. The next steps were accomplished in the State Museum of Natural History in Stuttgart. The specimens were dried by critical point drying. The mounted material was coated with a gold layer, examined, and photographed with a Zeiss EVO LS 15 scanning electron microscope.

\section{RESULTS}

\subsection{Bioassay}

There were no significant differences between the three groups of males with regard to the behavioral attributes "walking around the female and palpating the female" and "mounting the female's dorsum" (Figures 3 and 4).

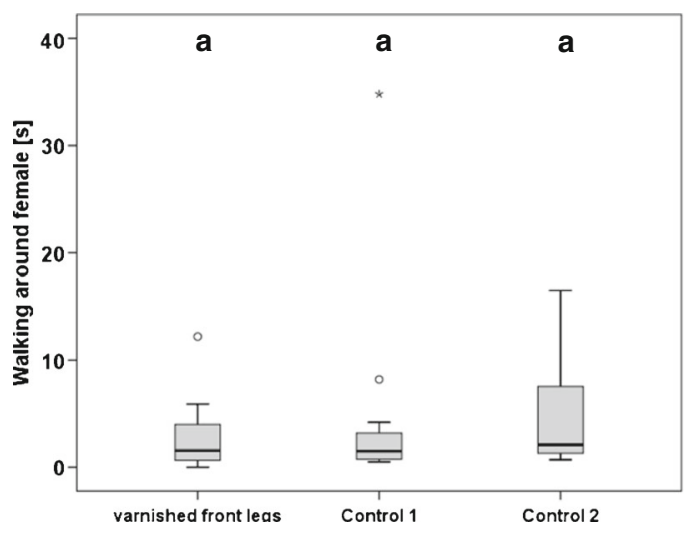

Figure 3. Duration of the behavioral attribute "walking around female" of three male groups (group 1: males with varnished front legs, $n=16$; group 2: control 1, males with varnished idiosoma, $n=16$; group 3 : control 2, untreated males, $n=24$ ) toward young attractive female mites in seconds. Asterisk marks extreme values. Circles mark outliner. Letters mark significant differences between the groups.

Both the untreated males and the males with the varnished idiosoma were attracted by the female mites and revealed the typical mating behavior. Males of each of these control groups spent,

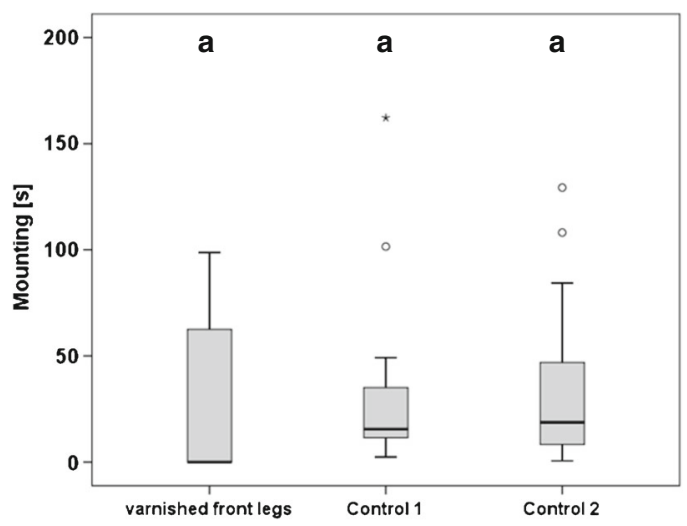

Figure 4. Duration of the behavioral attribute "mounting" of three male groups (group 1: males with varnished front legs, $n=16$; group 2: control 1, males with varnished idiosoma, $n=16$; group 3: control 2, untreated males, $n=24$ ) toward young attractive female mites in seconds. Asterisk marks extreme values. Circles mark outliner. Letters mark significant differences between the groups. 
on average, more than 1 min per trial at the female's venter in typical copulation posture. The copulation attempts of the untreated group were longer compared to the group with varnished idisosoma; however, these differences were not significant (Figure 5; $P>0.05$, Kruskal-Wallis test).

In contrast, male mites with the varnished front legs did hardly show any copulation attempts $(P<0.01$, Kruskal-Wallis test; Figure 5). In the untreated control group, all 24 males performed the typical copulation attempts with the females; in the group with the varnished idiosoma, 13 of 16 males showed this behavior, whereas only 2 of 16 males with varnished front legs showed short-time copulation attempts (Figure 5).

\subsection{SEM analysis}

Scanning electron microscope analysis of adult male mites confirmed the presence of structures on the front leg tarsi of the male mites that resembles clearly the sensory pit organ of female mites (Ramm and Böckeler 1989; Dillier et al. 2006; Figure 6).

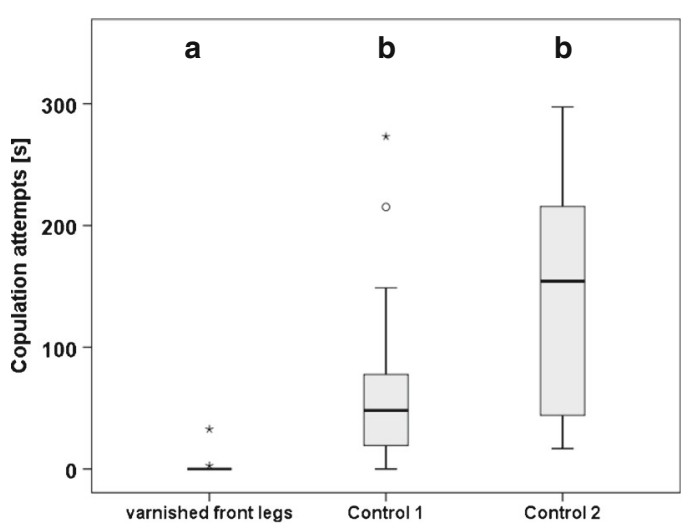

Figure 5. Duration of the copulation attempts of three male groups (group 1: males with varnished front legs, $n=16$; group 2: control 1, males with varnished idiosoma, $n=16$; group 3: control 2, untreated males, $n=24$ ) toward young attractive female mites in seconds. Asterisks mark extreme values. Circle marks outliner. Different letters mark significant differences between the groups.

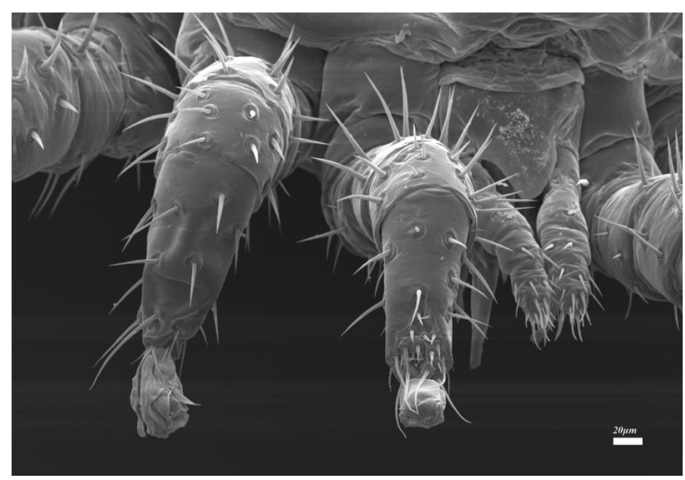

Figure 6. SEM photograph of a male mite, front view.

Likewise, the sensory pit organ of male mites consists of nine inner (S1 to S9) and nine outer sensilla (R1 to R9; Figure 7). The size of the male pit organ is about $16 \mu \mathrm{m}$ breadthways and $13 \mu \mathrm{m}$ lengthwise.

\section{DISCUSSION}

The mating within the sealed brood cell represents a crucial step of the reproductive cycle of $V$. destructor, because only mature female mites with filled spermathecae are able to produce female offspring and will therefore contribute to the growth of the parasite population (Harris and Harbor 1999; Ziegelmann and Rosenkranz 2014). The mating behavior is triggered by a recently identified female sex pheromone (Ziegelmann et al. 2013b). Freshly molted daughter mites are the most attractive females. Therefore, consecutive matings with the respective most recent daughter are ensured. We here show that crucial signals of the female mites that elicit the typical copulation behavior are perceived by a male sensory organ located on the front legs. If the front legs are varnished by nail polish, the respective male mite did not show copulation attempts any more. In the control males, nearly the entire idiosoma - and therefore a significant greater part of the body surface compared to the front legs-was covered by nail polish. Nevertheless, nearly all of these mites (control 1) revealed the typical copulation behavior - that is the so-called tip-over behavior from the dorsum to 


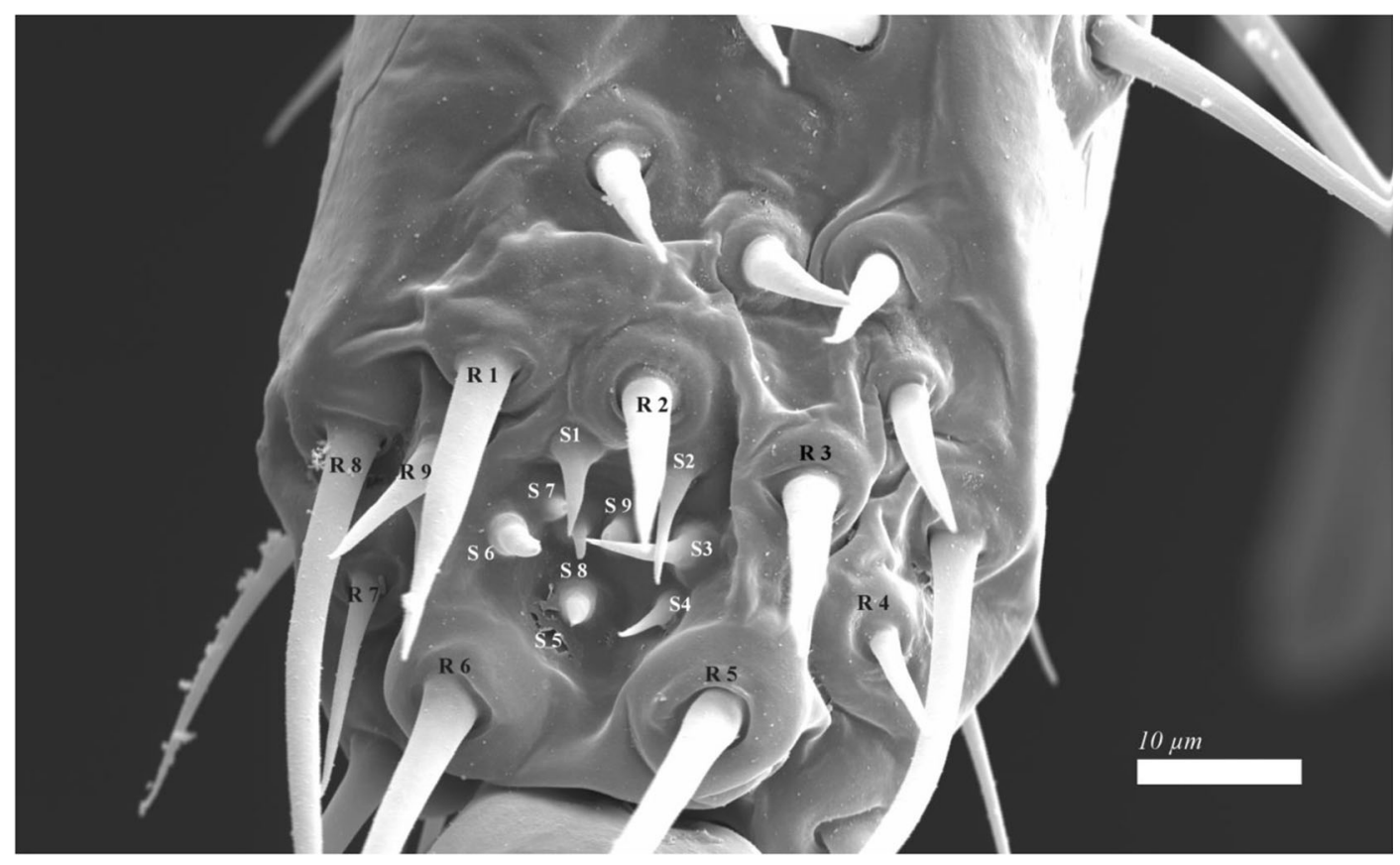

Figure 7. SEM photograph of the male sensory pit organ, front view of a male front leg tarsus.

the ventral side of the female (Ziegelmann et al. 2013a) - as recorded in the untreated males (control 2). We cannot exclude slightly negative effects of the nail polish, because male mites without nail polish showed a longer duration of copulation approaches with young females. However, male mites with varnished idiosoma were obviously ready to copulate with female mites.

Interestingly, the mounting activities as a first step of the copulation behavior were similar in all groups, respectively. This confirms the assumption of Ziegelmann et al. (2013b) that the mounting of a female's dorsum is a rather unspecific behavior and that only the crucial step of the copulation behavior - $i$. e., the movement to the female's venter as an imperative prerequisite for the transfer of the spermatophore into the female's gonopore-is elicited by the volatile female sex pheromone. The perception of this sex pheromone by olfactory receptors of the male might therefore be of particular significance for the triggering of the mating behavior. This assumption is supported by a behavioral bioassay where male mites were offered small seeds of Stachys sylvatica that are of similar size as a Varroa female. In the presence of components of the female sex pheromone, the male performed the typical copulation behavior even toward these seeds (Ziegelmann and Rosenkranz 2014, movie sequence in supplementary material) suggesting that mechanical stimuli from the cuticle of the female mite are not required to elicit the male's mating behavior. However, with our bioassay, we cannot observe the transfer of the spermatophore and it therefore cannot be excluded that mechanical cues are involved in this final step of the mating. For a definite clarification on the impact of volatile versus mechanical signals, electrophysiological analyses are required. Our results show that the respective receptors for the crucial female signals are located on the frontal part of the male's legs.

A first analysis of the male's front leg organ by SEM revealed a structure that clearly resembles the sensory pit organ as described from female Varroa mites (Ramm and Böckeler 1989; Dillier et al. 2006). In the class of arachnids, sensory 
organs serve for the perception of olfactory stimuli and are often located on the front leg tarsi. The best analyzed sensory organ in this class is the Haller's organ in the order of ticks (Ixodidae). It consists of a distal pit and a post capsule with an opening. Both the pit and the capsule possess sensilla (Foelix and Axtell 1972). Due to the microstructure of the sensilla, Foelix and Axtell (1972) assume that the sensilla in the capsule serve for perception of olfactory cues whereas the sensilla in the pit serve for the perception of humidity.

In Varroa males, the sensory pit organ resembles the female pit organ in size and in structure. The female pit organ is about $24 \mu \mathrm{m}$ breadthways and $17 \mu \mathrm{m}$ lengthwise in size (Ramm and Böckeler 1989) and hence similar in size to the male pit organ $(16 \mu \mathrm{m}$ breadthways and $13 \mu \mathrm{m}$ lengthwise). Furthermore, the male pit organ consists like the female one of nine inner and nine outer sensilla. In female mites, the sensilla $\mathrm{S} 1$ and S3 to S5 are identified as wall pore sensilla involved in the perception of volatiles (Ramm and Böckeler 1989). For more detailed information of the morphology of the male sensilla, further analyses by scanning electron microscopy and transmission electron microscopy are required. Again, electrophysiological studies could help to identify the further specificity of the sensilla for further compounds. Such studies have so far only been performed on the front leg of female mites in relation to host finding behavior (Eliash et al., 2014). Male mites spent their whole life cycle within the sealed brood cell without a phoretic phase on the adult bees (Rosenkranz et al., 2010). Therefore, it is likely that the function of the male's sensilla is limited to (i) finding the feeding place on the pupa and to (ii) trigger the mating behavior toward freshly molted daughter mites.

It could be of particular interest to identify the responsible male receptor for the sex pheromone perception and to analyze respective odorant binding proteins and the olfactory signaling pathway. Such knowledge might be used for a silencing of the respective receptor as it has already been demonstrated for some insects where mating behavior and host seeking could be blocked by the use of RNAi techniques (Zhang et al. 2013).

\section{ACKNOWLEDGMENTS}

We gladly thank Arnold Staniczek for his good cooperation and for providing the facilities of the State Museum. In particular, we are grateful to Karin WolfSchwenninger from the State Museum of Natural History Stuttgart for her indispensable technical support in the use of the scanning electron microscope. We thank the Federal Ministry of Food, Agriculture and Consumer Protection for providing financial support (51106.01-28-1-71.001-10).

Les acariens mâles (Varroa destructor) perçoivent la phéromone sexuelle des femelles grâce à leur fossette sensorielle située sur les tarses des pattes antérieures

comportement sexuel / Acari / organe olfactif

Männliche Varroa destructor Milben nehmen das weibliche Sexualpheromon mit dem Grubensinnesorgan auf den Tarsi der Vorderbeine wahr

Acari / Sexualpheromon / Grubensinnesorgan / Begattungsverhalten

\section{REFERENCES}

Anderson, D.L., Trueman, J.W.H. (2000) Varroa jacobsoni (Acari: Varroidae) is more than one species. Exp. Appl. Acarol. 24, 165-189

Boecking, O., Genersch, E. (2008) Varroosis - the Ongoing Crisis in Bee Keeping. J. Consum. Protect Food Saf. 3 (2), 221-228

Dillier, F.X., Fluri, P., Imdorf, A. (2006) Review of the orientation behavior in the bee parasitic mite Varroa destructor: Sensory equipment and cell invasion behavior. Rev. Suisse. Zool. 133 (4), 857-877

Donzé, G., Guerin, P.M. (1994) Behavioral attributes and parental care of Varroa mites parasitizing honeybee brood. Behav. Ecol. Sociobiol. 34, 305-319

Donzé, G., Herrmann, M., Bachofen, B., Guerin, P.M. (1996) Effect of mating frequency and brood cell infestation rate on the reproductive success of the honeybee parasite Varroa jacobsoni . Ecol. Entomol. 21, $17-26$

Eliash, N., Singh, N.K., Kamer, Y., Pinnelli, G.R., Plettner, E., Soroker, V. (2014) Can we disrupt the sensing of honey bees by the bee parasite Varroa destructor? PLoS ONE 9 (9), e106889. doi:10.1371/journal.pone.0106889

Foelix, R.F., Axtell, R.C. (1972) Ultrastructure of Haller's Organ in the Tick Amblyomma americanum (L.)*. Z. Zellforsch 124, 275-292 
Frey, E., Odemer, R., Blum, T., Rosenkranz, P. (2013) Activation and interruption of the reproduction of Varroa destructor is triggered by host signals (Apis mellifera). J. Invertebr. Pathol. 133 (1), $56-62$

Garrido, C., Rosenkranz, P. (2004) Volatiles of the honey bee larva initiate oogenesis in the parasitic mite Varroa destructor. Chemoecology 14, 193-197

Genersch, E., von der Ohe, W., Kaatz, H., Schroeder, A., Otten, C., Büchler, R., Berg, S., Ritter, W., Muehlen, W., Gisder, S., Meixner, M., Liebig, G., Rosenkranz, P. (2010) The German bee monitoring project: a long term study to understand periodically high winter losses of honey bee colonies. Apidologie 41, 332-352

Harris, J.W., Harbor, J.R. (1999) Low sperm counts and reduced fecundity of mites in colonies of honey bees (Hymenoptera: Apidae) resistant to Varroa jacobsoni (Mesostigmata: Varroaidae). J. Econ. Entomol. 92, 83-90

Hess, E., Vlimant, M. (1982) The tarsal sensory system of Amblyomma variegatum Fabricius (Ixodidae: Metastriata) I. Wall pore and terminal pore sensilla. Rev. Suisse Zool. 98, 713-729

Ifantidis, M.D. (1983) Ontogenesis of the mite Varroa jacobsoni in worker and drone honey bee brood cells. J. Apic. Res. 22, 200-206

Ifantidis, M.D. (1990) Re-examination of some parameters concerning reproduction of the mite Varroa jacobsoni Oud. Proceedings of the International Symposium on Resent Research on Bee Pathology, Ghent, Belgium, pp. 20-26

Le Conte, Y., Ellis, M., Ritter, W. (2010) Varroa mites and honey bee health: can Varroa explain part of the colony losses? Apidologie 41, 353-363
Ramm, D., Böckeler, W. (1989) Ultrastrukturelle Darstellungen der Sensillen in der Vordertarsengrube von Varroa jacobsoni (Acari). Zool. JB. Anat. 119, 221-236

Rehm, S.M., Ritter, W. (1989) Sequences of the sexes in the offspring of Varroa jacobsoni and resulting consequences for the calculation of the developmental period. Apidologie 20, 339-343

Rosenkranz, P., Aumeier, P., Ziegelmann, B. (2010) Biology and control of Varroa destructor. J. Invertebr. Pathol. 103, 96-119

Sonenshine, D.E., Taylor, D., Keith, A.C. (1986) Chemically mediated behavior in Acari: adaptations for finding hosts and mates. J. Chem. Ecol. 12, 1091-1108

Martin, S.J. (1994) Ontogenesis of the mite Varroa jacobsoni Oud. In worker brood of the honeybee Apis mellifera L. under natural conditions. Exp. Appl. Acarol. 18, 87-100

Ziegelmann, B., Lindenmayer, A., Steidle, J., Rosenkranz, P. (2013a) The mating behavior of Varroa destructor is triggered by a female sex pheromone. Apidologie 44, 314-323

Ziegelmann, B., Tolasch, T., Steidle, J.L.M., Rosenkranz, P. (2013b) The mating behavior of Varroa destructor is triggered by a female sex pheromone. Part 2: Identification and dose-dependent effects of components of the Varroa sex pheromone. Apidologie 44, 481-490

Ziegelmann, B., Rosenkranz, P. (2014) Mating disruption of the honeybee mite Varroa destructor under laboratory and field conditions. Chemoecology. doi:10.1007/ s00049-014-0155-4

Zhang, H., Li, H.C., Miao, X.X. (2013) Feasibility, limitation and possible solutions of RNAi-based technology for insect pest control. Insect Sci. 20, 15-30 